\title{
Quality of Life and Challenges Experienced by the Surviving Adults With Transfusion Dependent Thalassaemia in Malaysia: A Cross Sectional Study
}

Wai Cheng Foong ( $\nabla$ wcfoong@rcsiucd.edu.my)

Department of Paediatrics, RCSI \& UCD Malaysia Campus https://orcid.org/0000-0003-2138-7040 Kooi Yau Chean

Department of Family Medicine, RCSI \& UCD Malaysia Campus

Fairuz Fadzilah Rahim

Department of Public Health, RCSI \& UCD Malaysia Campus

Ai Sim Goh

Haematology Unit, Hospital Pulau Pinang

Seoh Leng Yeoh

Department of Paediatrics, Hospital Pulau Pinang

Angeline Aing Chiee Yeoh

Department of Paediatrics, Hospital Seberang Jaya

\section{Research Article}

Keywords: Thalassaemia, Quality of life, Healthy days, Employment

Posted Date: June 2nd, 2021

DOI: https://doi.org/10.21203/rs.3.rs-561280/v1

License: (1) This work is licensed under a Creative Commons Attribution 4.0 International License. Read Full License

Version of Record: A version of this preprint was published at Health and Quality of Life Outcomes on January 8th, 2022. See the published version at https://doi.org/10.1186/s12955-021-01897-4. 


\section{Abstract \\ Background}

Improvement in medical management has enabled transfusion dependent thalassaemia (TDT) patients to survive beyond childhood, building families, and contributing to the labour force and society.

Knowledge about their adult life would provide guidance on how to support their needs. This study aims to explore the general well-being of adults with TDT, their employment status and challenges.

\section{Methods}

We contacted all regional Thalassaemia societies in Malaysia to invite TDT members aged 18 or over to participate. Participants were also recruited from the two participating hospitals. A self-administered questionnaire including 'CDC Healthy-days', WHOQOL-BREF and employment measurements was used. Multiple linear regression models were fitted with associations adjusted for several potential confounders.

\section{Results}

Of the 196 participants, almost half (45\%) had comorbidities and $20 \%$ suffered multiple types: bonerelated $(13 \%)$, hormonal $(12 \%)$, cardiac $(3 \%)$ and infections $(2 \%)$, resulting in $23 \%$ seeking treatment more than twice monthly. Within a month, they suffered from a mean 3.1 (SD 3.0) days of feeling unhealthy physically, a mean 2.6 (SD 3.5) days mentally unhealthy and their normal daily activities performance were affected for approximately 2.5 (SD 3.3) days - leading to $36 \%$ being jobless and $38 \%$ of those with a job receiving salaries below RM1000. The mean quality of life (QOL) score (mean (SD) for each QOL domain was: physical health 62.6 (15.5), psychological health 64.7 (15.7), social relationship 64 (15.9), environmental health 60.8 (16.7). Frequent activities limited days, being single, unwillingness to disclose thalassaemia status, presence of comorbidities, discrimination experiences and perceptions about employment difficulties were associated with lower QOL scores. Dissatisfaction with health service provision, conflicting judgement in prioritising between health and job, and poor public empathy were expressed.

\section{Conclusion}

Adults with TDT appeared to be fairly positive about their life in spite of high number of dysfunctional days and had perceptions that health services do not meet their needs. They continued to face life disruption in a rather non-supportive community. Supportive approaches and life-skill training are necessary where interventions should be started during childhood. Adjustment to health services should be considered. 


\section{Introduction}

Thalassaemia is the commonest inherited blood disorder in Malaysia with a total population of 8681 in 2018. The commonest clinical subtype of thalassaemia in Malaysia is $\mathrm{Hb}$ E-beta thalassaemia (34.37\%), followed by beta thalassaemia major (33.52\%), Hb H disease (18.26\%), beta thalassaemia intermedia $(9.37 \%)$ and others $(4.48 \%)$ [1]. The first three subtypes, especially beta thalassaemia major are more serious in clinical presentation and can cause these people a life-long need for regular blood transfusion starting at tender age, a status termed transfusion dependent thalassaemia (TDT).

The prolongation in life expectancy for people with TDT through advancement and availability of necessary treatment have enabled them to experience adulthood [2-4]. In 2018, 92\% were still alive in Malaysia and around $44 \%$ have reached adulthood. They have been receiving assistance such as provision of free medical treatment [5] and mass community screening. The TDT population continues to grow, though there is a decline in the number of new cases; many more will be entering adulthood soon [6].

A report has shown that the global disability-adjusted life years increased by $40 \%$ for non-communicable diseases when life-expectancy is prolonged [7]. This could be a reflection of the future that people surviving with TDT have to face. People with TDTs are known to have expressed their concerns about how they have struggled with life and how they have been marginalized $[8,9]$. The perception of having thalassaemia has also been negative since childhood, a burden to the patient, family and nation $[10,11]$. The social media continue to publish their challenges intermittently despite the government's contemporary assistance [12-15]. Therefore, it is timely to explore their transition to adulthood from childhood and how they fare during adulthood in the era when much medical assistance is provided. We conducted this study to determine their clinical and psychosocial burden, including employment status and their actual needs during adulthood. We also aimed to assess if there is another area of focus for the healthcare team to support TDTs during their transition to adulthood.

\section{Methods}

\section{Study Design and study setting}

This was a cross sectional study and eligible participants were recruited through convenient sampling.

Participants were recruited between August 2016 and December 2016 by the participant's attending doctor, nurse or selected regional site coordinators, a representative from each thalassaemia society.

Geographically there are 13 states in Malaysia where Sabah in East Malaysia, Kedah in Northern Malaysia and Selangor are the top 3 states with the highest prevalence of haemoglobinopathy [1]. Almost all states have formed a thalassaemia society but the level of activities and cooperation differs, depending on remoteness of the place and number of members. These thalassaemia societies have representatives with The Federation of Malaysia Thalassaemia Societies, another non-government 
organisation. Investigators got in touch with each thalassaemia society through these contacts. Invitation letters were sent to inform them about the study. A representative from each society was chosen to be briefed about the aim, conduct of the study and trained on recruitment process. Once a written consent was obtained from the participants, they were trained to guide the participants to either a soft or hard copy of the questionnaires. They were told not to be involved in the participant's decision in any way.

Doctors and nurses of the Thalassaemia Clinic in two participating public hospitals in Penang, Malaysia were also involved in the recruitment. They received similar briefings and training, and were told not to be involved in the participant's decision in any way.

\section{Participants}

Participants had transfusion dependent thalassaemia as diagnosed by their doctors at the time of recruitment, aged 18 years and above, and could independently answer written questionnaires. They were patients from the thalassaemia units of two hospitals in Penang, Malaysia and members from all registered regional thalassaemia societies in Malaysia.

\section{Data collection}

After consent was obtained, participants were given either an electronic link or a hard copy of a selfadministered questionnaire to answer. The questionnaire consisted of sections on socio-demographics and their health status, well-being, quality of life and free text on employment, challenges and healthcare systems. The questionnaires were set in three languages, English, Malay and Chinese. The Malay and Chinese versions were translations of the English version. The translations where cross-checked, back translated and piloted on a few patients by investigators before the study was conducted. Participants were given a choice to choose depending on their language literacy. If they chose to answer in hard copies, they were instructed to place their answered questionnaire in sealed envelopes. The respective representatives of the state's thalassaemia society would collect the answered sealed questionnaires and send them back to the investigators.

All responses answered via electronic link would be automatically stored at a pre-set google form which could only be accessed by investigators. As for the hard copies, site-coordinators would collect the sealed envelopes with answered copies and then send the collection as bulk mail back to investigators by post.

\section{Sample size calculation}

We used a survey sample size calculator set at $95 \%$ confidence interval and $5 \%$ level of significance. Based on these reports [16, 17], we estimated a sample size of 344 respondents for this study. A total of 450 questionnaires were distributed to account for the possibility of approximately $20 \%$ with un-usable data.

\section{Data Collection Instrument}

Participants filled out a structured, pre-validated questionnaire which consisted of four sections: 
a) Socio-demographic characteristics: Age, gender, race, type of thalassaemia, co-morbidity, medication, marital status, education, income and occupation.

b) CDC 'Healthy-days' measurement [18]: This is a self-rated evaluation about perceived burden of own health for both acute and chronic health conditions, and in this study, it was on thalassaemia. There are 4 questions which can be used to estimate people with thalassaemia's healthy years of life and healthadjusted life expectancy and identify any significant health differences between groups (Appendix I). Responses are in the form of number of affected days in a month and a 5-point Likert scale about their perception on general health.

c) WHOQOL-BREF [19]: This is a set of questionnaires which comprised of 4 domains (physical health, psychological health, social-relationship, environmental health) that revolved around feelings on QOL, health, or other areas of in life. Each domain comprised of multiple questions on the specified area. Responses are graded on a scale 1 to 5 and a more positive impact will have a higher score, thus a score closer to 100 denotes a better quality of life for a particular domain.

d) Perception on healthcare services and employment: The questions included job descriptions, job's satisfaction, monthly salary, monthly off-days, support at work, discrimination at work, disclosure of disease and willingness to disclose disease with colleagues. Participants were given the opportunity to elaborate on any questions asked including areas which could be related to healthcare services in the form of free field texts.

All questions used had been tested in a separate group of adult thalassaemia patients not involved in the study.

\section{Data analyses}

In reporting descriptive statistics, continuous data was presented as mean with standard deviation (SD) and categorical data presented as frequency $(n)$ with percentage (\%). Chi-square analysis $\left(X^{2}\right)$ was conducted to compare the baseline characteristics according to the age at diagnosis and the age receiving first blood transfusion. Data obtained from CDC 'Healthy-days' and WHOQOL-BREF were displayed using the respective intended unit or scores.

Linear regression analysis was used to determine potential factors associated to their QOL. All study factors were identified as clinically important variables. Simple linear regression was used to identify possible factors associated with QOL. The factors were then fitted into multiple linear regression models based on each QOL domain, adjusting to the effect of other study factors. The results from linear analysis were reported as coefficient, its $95 \%$ confidence interval $(\mathrm{Cl})$ and $p$-value. All statistical analysis was done using Stata-13 [20]. A $p$-value of less than 0.05 was taken as a statistically significant finding.

\section{Results}


Of the 450 questionnaires distributed to 13 states of Malaysia, 217 were returned. Twenty-one responses were excluded because less than $80 \%$ completion of the questionnaire. The final number of questionnaires analysed was 196. The responders came from nine out of the 13 states.

There were fairly equal proportion of males $(n=87,44 \%)$ and females $(n=109,56 \%)$ participants. The mean age was 27 (SD7.4). They were mainly of the Malay ethnicity $(n=121,62 \%)$. Majority of them suffered from beta thalassaemia major $(n=126,64 \%)$, followed by HbE beta thalassaemia $(n=59,30 \%)$ and $\mathrm{HbH}$ disease) $(\mathrm{n}=11,6 \%)$ (Table 1).

We found $45 \%(n=80)$ of the participants were suffering from at least one complication of thalassaemia or the treatment they have received (Table 1). Highest co-morbidity on the list was musculoskeletal problems such as osteoporosis-osteopenia syndrome, bone pain or fractures or disfigurements, followed by endocrine issues such as diabetes mellitus, hypothyroidism or infertility and cardiac abnormalities. Four had contracted transfusion related infections and 16 had various types of complications. Four were stressed with life and another 17 did not make any disclosure. Hence, $82 \%(n=161)$ were on some form of medication in addition to their regular blood transfusion and folate supplements. Almost all $(97 \%)$ participants were on iron chelating agents to prevent iron overload. (Table 1).

\section{Effects of having chronic anaemia and dependency on blood transfusion}

We found only $62 \%$ of those participants with beta thalassaemia major to be diagnosed and transfused before the age of 2 years. Another $12 \%$ was diagnosed as having Thalassaemia before age of 2 but having had their first transfusion after 2 years old and the remaining $26 \%$ were diagnosed and first transfused after 2 years (Table 2). The majority of those with thalassaemia intermedia ( $\mathrm{HbE}$ beta thalassaemia and $\mathrm{HbH}$ disease) manifested much later and 7 of them needed medical care before age of 2 years. At the time of this study, all of them required a blood transfusion at least once a month, which required them to be at the hospital. Further hospital visits were expected for various reasons such as doctor/pharmacist consultations and investigation procedures, thus causing 58\% $(n=114)$ of the participants seeking hospital visits twice or more per month. There were significantly more singles among those who were diagnosed and were transfused blood earlier $(p \leq 0.001)$ but no significant association between the timing of diagnosis and transfusion with co-morbidity, education, employment status, general health perceptions and satisfaction to health (Table 2).

\section{Self-perception of general health and quality of life}

A majority perceived themselves as healthy $(74 \%)$. About half were satisfied with their general health $(n=$ $100,51 \%)$. Their quality of life across all 4 domains was above average with psychological health obtaining the highest score at 64.7 (15.7) and environmental health getting the lowest score at 60.8 (16.7) (Table 3). However, in a month, the participants considered a mean (SD) of 3.1 (3.0) days to be physically unfit, 2.6 (3.5) days to have some psychological issues and around 2.5 (3.3) days when their daily activities were affected and limited. 


\section{Self-perception on healthcare services and employment}

At the time of the study, 126 (64\%) participants held a job and were earning a living. A majority earned between RM1000 to RM2000 a month ( $n=55,44 \%)$, followed by those earning below RM1000 a month $(n=48,38 \%)$ and $4(3 \%)$ participants did not disclose. Eight of them were not confident in retaining their current employment. The remaining $(n=70)$ were not earning a living because they had never held any job $(n=19,27 \%)$, had been retrenched for the past 2 years $(n=27,39 \%)$ or were still studying $(n=24$, $34 \%)$. Those who were still holding or had held a job previously had shared their thalassaemia condition with colleagues $(n=104)$, were willing to disclose their thalassaemia status $(n=56)$, experienced difficulties in their job because of thalassaemia $(n=48)$ and had been discriminated before for having thalassaemia $(n=85)$. There is no significant association between the number of activity limited days with their perception of employment difficulties because of thalassaemia $(p=0.06)$. We also found some participants (excluding students, $n=172$ ) have chosen not to answer questions on whether they had discussed thalassaemia with colleagues before $(n=21)$, willingness to disclose $(n=3)$, experienced difficulties in obtaining or retaining job $(n=30)$, work place support $(n=48)$ and presence of discrimination $(n=28)$. Two students had worked briefly before and one of them experienced workplace discrimination.

There were 67 responses to the free text comments on their healthcare services and employment. The main response $(n=35)$ was a negative perception of having thalassaemia and how it had affected their job potentials. There were 21 responses which pleaded for more employment opportunities or promotions for people with thalassaemia and that there should not be any workforce discrimination against them. Dissatisfaction with health service provision such as non-flexi treatment hours or no dedicated clinics, conflicting judgement or ability in prioritising between health and job, and poor public empathy were expressed. They also wanted more community awareness and support $(n=6)$ together with a better health professional-patient relationship in order to enable them to cope with having thalassaemia and to assist in planning for their future $(n=5)$.

\section{Factors associated with quality of life (WHOQOL-BREF)}

Table 4 showed the factors associated with QOL. Physical health was affected by the greatest number of factors with the presence of discrimination at workplace the main negative factor $(-10.7995 \% \mathrm{Cl}(-15.80$, $-5.77) \mathrm{p}=0.006)$ and having a higher education level the main positive factor $(5.17,95 \% \mathrm{Cl}(1.01,9.34) \mathrm{p}$ $=0.015)$. The main factor that affected all domains was having days with mental issues, discrimination at workplace, perception that thalassaemia was a job burden and willingness to disclose one has thalassaemia. The first three factors had reduced the scores for each domain while willingness increased the scores.

When multiple linear regression was applied, willingness to disclose remained significantly the main predictive factor to increase the scores for all domains while presence of workplace discrimination was shown significantly affecting mainly the social relationship scores, followed by psychological and 
environmental health scores but no longer affecting physical health scores. Some of the other factors continued to play a role in lowering the scores for certain domains but to a lesser degree.

\section{Discussion}

This study has shown the positive effect brought about by the improved resources given by the Ministry of Health Malaysia $(\mathrm{MOH})$ to people with thalassaemia. The majority with this disability have a fairly positive perception about their general health and were satisfied with their current status. Their quality of life (QOL) was shown reaching scores above average, a similar finding noted in countries where health authorities have provided substantial aids to people with thalassaemia in terms of provision of transfusion and chelation [21]. According to Silva 2014 et al, the QOL scores obtain were considered satisfactory [22].

Their lifestyles have shown improvement in the number of participants who gained employment, started their own family and attained higher education. They seemed to be coping fairly well with the disabilities brought by thalassaemia and its related complications. This is a remarkable achievement when compared with how they would have perceived life and struggled 10 years ago [5]. People with thalassaemia globally have shown that they have the potential to succeed when given the opportunity and recognition [23].

Although their health has improved, the fairly high number of participants with co-morbidities and days when daily activities were limited suggest that their health status may not be at par with people without thalassaemia, a similar finding with another study [24]. The frequent need for hospital visits to care for their health and the high number of days with limitation to their daily activities have created difficulties for them to develop to their full potential. Any additional days are found to lower the QOL scores significantly. From the multiple linear regression of factors affecting QOL, it is likely that all the QOL scores in this study will drop further if no measures are taken into account to reduce their challenges. This suggests a possibility that the many challenges faced by people with TDT have yet to be overcome despite the provision of advanced contemporary treatment and that they have struggled since childhood [25-27]. In fact, our QOL scores for each domain are lower than the scores obtained from studies done in another country with government support for their thalassaemia population [25]. While the participants in this study are trying to manage their health as seen in other published articles [28-30], their coping abilities may burn out when support and guidance from health care and society remain inadequate. Studies have reported that thalassaemic adolescents have negative coping abilities and used inappropriate approach when faced with stresses in life [31], probably due to over-protective parents and over-dependency on their parents since childhood [10]. On the other hand, an endless assistance could make them less dependent on themselves. Although this study did not look at the upbringing and coping strategies of the participants, from the free field text, it seemed that adult TDTs need to juggle between staying healthy with the disease and doing well with normal activities. Perhaps it is timely that the healthcare system should now consider assisting them to be more independent in self-care towards a near-normal life routine of a person without TDT. Life-training skills and psychological treatment are 
suggested management to overcome these shortcomings [32,33]. These should start during their childhood and perhaps extended to their caregivers as indicated by other studies [34,35]. With proper training and guidance, they may fare as well as if not better to than healthy people [36].

In addition, there is a need for a resource such as a one-stop centre where people with thalassaemia could seek support to assimilate themselves better with the society and learn to be more independent in control of their health. This is because the participants in this study still perceived that having thalassaemia as a burden in their working and family lives. To reduce this negative perception, resources should improve the provision of good intersectoral coordination and capabilities in order to address the ever-changing demands of society and the needs of these people. The existing resources could reform their services to provide appropriate and effective care by a multidisciplinary expert medical team in reference centre - all in a same hospital visit and time.

We found a marked drop in the number of participants who remained willing to share their thalassaemia status with other people after disclosing it previously. While we did not further explore reasons for this, the most likely reason was that there could be a sense of hesitancy, insecurity and low self-esteem towards an unsupportive environment and community who may not be aware of their capabilities. Another possible reason could be the effect of the on-going health campaigns which have focused mainly on prevention and the importance of screening, and may have unintendedly painted a negative image of them as problematic people with special needs. Indeed, the environmental health QOL score in this study is noted to be the lowest. Future studies could be done to explore the validity of these explanations.

Otherwise, perhaps it is timely to revise the content of public and employer awareness about thalassaemia to minimise any misunderstandings on their potential capabilities and create a better social and environmental support which is crucial for a healthy social and professional integration. This calls for a better planning system to have these patients recognized as valuable assets to the community and provide them equal opportunities towards a full social and professional life. To address this inequality in environmental and social health, it is suggested that the local government should encourage other sectors to provide equal employment rights while helping them to juggle with their health management. The existing public awareness of the condition should be continued but perhaps the emphasis should not be only on prevention but also what or how this group of people can contribute to society. Publishing the success stories of some patients [37-39] could boost not only their self-esteem but also perhaps change the degree of stigmatization of them that is still present in some communities. With better public understanding and support for their needs, they will be better accepted and improve their assimilation into the society and workforce. As one of the participants said "I am as capable like everyone else, it's just that I need a little extra blood every month".

The ability to obtain higher educational level has been a value associated with potential higher social level, better QOL and higher income [25, 40, 41]. A systematic review has shown that lower health literacy is associated with higher mortality, though not affecting QOL[42]. Of those unemployed in this study, $34 \%$ 
were actually continuing their education at tertiary level. This shows that the participants are trying to improve their life quality and that they are moving forward towards a brighter future.

\section{Strength of the study:}

This study provides comprehensive data about the well-being of the adult population with TDT in the whole of Malaysia using validated questionnaires. Although there are other studies on this matter, the population of interest in these studies was more focused at selected regional places. This study also represents the voices of people with TDTs that need to be heard. Knowledge of their lifestyles could provide guidance on how to support their needs in adulthood and for healthcare services to support them towards a goal of near normal independent life. Hence, to further improve the delivery of the healthcare system with the ultimate aim of increasing their self-sufficiency.

\section{Limitations of the study}

The main limitation in this study is that it could not be generalized to larger population due to the small sample size and inequal distribution of samples collected. We did not have the data on the actual thalassaemia population in Malaysia at the time of the study for proper sample size calculation. The newly published thalassaemia registry [1] has registered a total of 1603 adults with TDT and our sample size represents only $15 \%$ of the population. Although the sample size is small, we have managed to collect some data from the 2 regions with the highest prevalence. We also faced difficulties reaching most TDTs for many refused to participate due to reasons not disclosed to us nor the research assistants. Another limitation is that we could not do any comparison with healthy adults. The WHOQOLBREF questions were also rather lengthy and sensitive because some of the participants chose not to answer some questions in the sections relating to social relationship and environmental health. Perhaps another healthcare and QOL tool specially tailored for thalassaemia such as ThALI should be used [43].

\section{Conclusion}

The majority of the participants in this study seemed to be coping with the disease and moving on with adulthood with a fairly high quality of life despite high number of unhealthy days with limitation to daily activities. They continue to face suppression of their potential capabilities and other challenges. Our findings give insight into the needs of these people, how delivery of public awareness could be improved, and the role both employers and themselves could play to support each other. Their future now not only depends on how to stay healthy but also how live a near normal life just like the general population without chronic illnesses.

\section{List Of Abbreviations}

QOL: quality of life

TDT: transfusion dependent thalassaemia 
$\mathrm{MOH}$ : Ministry of Health

CDC: Centers for Disease Control and Prevention

WHOQOL-BREF: The international version of the instrument issued by the World Health Organization (in the English, Malay and Chinese languages)

\section{Declarations}

This study was registered with the National Medical Research Register (NMRR No: NMRR-15-481-25274) and ethical approval was obtained from the Medical Research \& Ethics Committee, Ministry of Health Malaysia (KKM/NIHSEC/P15-583). Written consent was obtained from the participants prior to the commencement of study.

\section{Funding}

This study is funded by RCSI \& UCD Malaysia Campus.

\section{Conflict of interest}

The authors declared that they may be the managing doctors for some of the participants but otherwise have no other conflict of interest.

\section{Abstracts / posters}

This study has been presented at the Global Globin 2020 Challenge (GG2020) Conference, July 2018 as an e-poster and the abstract published online in the Asian Journal of Medicine and Biomedicine (AJMB) website ((https://journal.unisza.edu.my/ajmb/index.php/ajmb/issue/view/5) in 2018. It has also been presented as oral free paper presentation at the $40^{\text {th }}$ Malaysian Paediatric Association (MPA) Annual Congress, September 2018. However, the full manuscript has not been published elsewhere, nor is it currently under consideration for publication anywhere else.

\section{Author information}

\section{Affiliations}

Department of Paediatrics, RCSI \& UCD Malaysia Campus

Wai Cheng Foong

Department of Family Medicine, RCSI \& UCD Malaysia Campus

Kooi Yau Chean 
Department of Public Health Medicine, RCSI \& UCD Malaysia Campus

Fairuz Fadzilah Rahim

Haematology Unit, Department of Medicine, Hospital Pulau Pinang, Ministry of Health Malaysia

Ai Sim Goh

Department of Paediatrics, Hospital Seberang Jaya, Ministry of Health Malaysia

Seoh Leng Yeoh

Department of Paediatrics, Hospital Pulau Pinang, Ministry of Health Malaysia

Angeline Aing Chiee Yeoh

Corresponding author

Correspondence to Wai Cheng Foong

E-mail: wcfoong@rcsiucd.edu.my

\section{Author's contributions}

WCF and KYC contributed to the design of work, training of the research assistants, participant recruitment, analysis and interpretation of data, design of tables, drafting and modifying of the manuscript, and revise the final version of the manuscript. FFR contributed to analysis and interpretation the data, design of tables, drafting and modifying the manuscript and revising the final version of the manuscript. ASG, SLY and AACY contributed to the design of work, training of research assistants, and drafting and modifying the manuscript. All authors have read and approved the final manuscript.

\section{Acknowledgment}

The authors would like to acknowledge Drs Christin Sing Ai Wong, Kah Yan, Loh, Sing Yuan Fua and all the secretariat of individual thalassaemia societies in Malaysia and Federation of Malaysia Thalassaemia Societies for their assistance in participant recruitment; Medical Research \& Ethics Committee, Ministry of Health Malaysia (KKM/NIHSEC/P15-583) for the ethical approval and RCSI \& UCD Malaysia Campus for funding support.

\section{Consent for publication}

The authors would like to thank the Director General of Health Malaysia for his permission to publish this article. Participants have consented to have their biodatas published. All authors have agreed to published the manuscript in its current form. 


\section{References}

1. Malaysian Thalassaemia Registry report 2018. In: Malaysian Thalassaemia Registry Committee Ministry of Health M, editor. Ministry of Health, Malaysia2019. p. 0-320.

2. Borgna-Pignatti C, Cappellini MD, De Stefano P, Del Vecchio GC, Forni GL, Gamberini MR, et al. Survival and complications in thalassemia. Annals of the New York Academy of Sciences. 2005;1054:40-7.

3. Modell B, Khan M, Darlison M. Survival in beta-thalassaemia major in the UK: data from the UK Thalassaemia Register. Lancet (London, England). 2000;355(9220):2051-2.

4. Telfer P. Update on survival in thalassemia major. Hemoglobin. 2009;33 Suppl 1:S76-80.

5. Shafie AA, Chhabra IK, Wong JHY, Mohammed NS, Ibrahim HM, Alias H. Health-related quality of life among children with transfusion-dependent thalassemia: A cross-sectional study in Malaysia. Health and Quality of Life Outcomes. 2020;18(1):141.

6. Ngim CF, Ibrahim H, Lai NM, Ng CS. A single centre study on birth of children with transfusiondependent thalassaemia in Malaysia and reasons for ineffective prevention. Prenatal diagnosis. 2015;35(1):51-9.

7. Global, regional, and national disability-adjusted life-years (DALYs) for 359 diseases and injuries and healthy life expectancy (HALE) for 195 countries and territories, 1990-2017: a systematic analysis for the Global Burden of Disease Study 2017. Lancet 2018. 2017;392(10159):1859 - 922.

8. Loizou C PC, Beck S, Karekla M, Talias M, Christou S, Michaelidou N, Constantinou C. How life would be without thalassaemia: patients' perceptions. Cyprus Review. 2016;28(1):33-48.

9. Ansari S, Baghersalimi A, Azarkeivan A, Nojomi M, Hassanzadeh Rad A. Quality of life in patients with thalassemia major. Iranian journal of pediatric hematology and oncology. 2014;4(2):57-63.

10. Mufti GE, Towell T, Cartwright T. Pakistani children's experiences of growing up with betathalassemia major. Qualitative health research. 2015;25(3):386-96.

11. Wahab IA, Naznin M, Nora MZ, Suzanah AR, Zulaiho M, Faszrul AR, et al. Thalassaemia: a study on the perception of patients and family members. The Medical journal of Malaysia. 2011;66(4):326-34.

12. Hamid SSA. Tumbersaran dia beradik terganggu. Metro Harian. 201719 May 2017;Sect. MyMetro Utama.

13. Noor HM. 'Kenapa saya kena pergi hospital setiap bulan...'. Berita Harian Online. 201714 December 2017; Sect. Keluarga.

14. Tanzizi NH. Tiga beradik derita talasemia major. Berita Harian. 201823 January 2018.

15. Zulkipli NL. RM3 juta rawat setiap pesakit Thalassaemia Berita Harian. 201810 November 2018;Sect. Nasional.

16. Nor Sb. Thalassemia in Pregnancy - Screening for thalassaemia Malaysia, Health Online Unit MoHM; 201923 August 2019. 
17. Current population estimates, Malaysia, 2014 - 2016 [press release]. Department of Statistics, Malaysia, 22 July 20162016.

18. Barile JP, Reeve BB, Smith AW, Zack MM, Mitchell SA, Kobau R, et al. Monitoring population health for Healthy People 2020: evaluation of the NIH PROMIS ${ }^{\circ}$ Global Health, CDC Healthy Days, and satisfaction with life instruments. Quality of life research : an international journal of quality of life aspects of treatment, care and rehabilitation. 2013;22(6):1201-11.

19. Skevington SM, Lotfy M, O'Connell KA. The World Health Organization's WHOQOL-BREF quality of life assessment: psychometric properties and results of the international field trial. A report from the WHOQOL group. Quality of life research : an international journal of quality of life aspects of treatment, care and rehabilitation. 2004;13(2):299-310.

20. StataCorp. Stata Statistical Software: Release 13. College Station, TX: StataCorp LP. 2013.

21. Telfer P, Constantinidou G, Andreou P, Christou S, Modell B, Angastiniotis M. Quality of life in thalassemia. Annals of the New York Academy of Sciences. 2005;1054:273-82.

22. Silva PAB, Soares SM, Santos JFG, Silva LB. Cut-off point for WHOQOL-bref as a measure of quality of life of older adults. Revista de Saúde Pública. 2014;48:390-7.

23. Bozkurt G. Results From The North Cyprus Thalassemia Prevention Program*. Hemoglobin. 2007;31:257-64.

24. Sobota A, Yamashita R, Xu Y, Trachtenberg F, Kohlbry P, Kleinert DA, et al. Quality of life in thalassemia: a comparison of SF-36 results from the thalassemia longitudinal cohort to reported literature and the US norms. American journal of hematology. 2011;86(1):92-5.

25. Gan GG, Hue YL, Sathar J. Factors Affecting Quality of Life in Adult Patients with Thalassaemia Major and Intermedia. Annals of the Academy of Medicine, Singapore. 2016;45(11):520-3.

26. Pouraboli B AH, Abbaszadeh A, Kazemi M. The Burden of Care: Experiences of Parents of Children with Thalassemia. Journal of Nursing and Care. 2017;6(2):8.

27. Sazlina S-G, Ymy A, Juni M. PREDICTORS OF HEALTH RELATED QUALITY OF LIFE AMONG CHILDREN AND ADOLESCENTS WITH BETA THALASSEMIA IN THREE HOSPITALS IN MALAYSIA: A CROSS SECTIONAL STUDY. International Journal of Public Health and Clinical Sciences. 2015;2:2289-7577.

28. Ali IAM. Call for weekend transfusion. The STAR. 201810 July 2018;Sect. Metro news.

29. Ismail A, Campbell MJ, Ibrahim HM, Jones GL. Health Related Quality of Life in Malaysian children with thalassaemia. Health Qual Life Outcomes. 2006;4:39.

30. Mohd Ibrahim H, Muda Z, Othman IS, Mohamed Unni MN, Teh KH, Thevarajah A, et al. Observational study on the current status of thalassaemia in Malaysia: a report from the Malaysian Thalassaemia Registry. BMJ open. 2020;10(6):e037974.

31. Abbasi S, Shahriari M, Ghanavat M, Talakoub S, Mosavi AsI FS, Hemati Z. The Relation between Different Aspects of Quality of Life with Coping Style in Adolescents with Thalassemia in Comparison to a Healthy Group. International journal of hematology-oncology and stem cell research. 2020;14(1):19-26. 
32. Anie KA, Massaglia P. Psychological therapies for thalassaemia. Cochrane Database Syst Rev. 2014;2014(3):Cd002890.

33. Peter O. Skills training for six thalassaemia patients. Daily Express. 20204 January 2020;Sect. Sabah news.

34. Biswas B. NN, Basu K., Dasgupta A., Paul B., Basu R., editor Predictors of quality of life of beta thalassaemia children: an epidemiological study. 60th Annual Conference of Indian Society of Hematology \& Blood Transfusion (ISHBT) October 2019; 2019: Indian J Hematol Blood Transfus (2019)

35. Sadeghloo A, Shamsaee P, Hesari E, Akhondzadeh G, Hojjati H. The effect of positive thinking training on the quality of life of parents of adolescent with thalassemia. International Journal of Adolescent Medicine and Health. 2019(0):20190159.

36. Zani B, Prati G. Psychosocial functioning in adults with beta-thalassaemia major: evidence for resilience. Journal of health psychology. 2015;20(4):380-92.

37. Bagang E. Plucky survivors. New Sabah Times. 20165 August 2016.

38. Jawing J. Emelyne menangi perjuangan melawan penyakit talasemia Utusan Borneo Online. 20185 October 2018;Sect. World.

39. Raman SNARb. Let's more to the better future. Thalassaemia International Federation. 2018.

40. Carvacho H, Zick A, Haye A, González R, Manzi J, Kocik C, et al. On the relation between social class and prejudice: The roles of education, income, and ideological attitudes. European Journal of Social Psychology. 2013;43(4):272-85.

41. Jae-Hyun K, Yoo K-B, Park E-C, Lee SG, Kim TH. Combined effects of education level and perceived social class on self-rated health and life satisfaction: Results of Korean labor and income panel study wave 8-wave 15. Health and Quality of Life Outcomes. 2015;13.

42. Neter E, Brainin E. Association Between Health Literacy, eHealth Literacy, and Health Outcomes Among Patients With Long-Term Conditions: A Systematic Review. European psychologist. 2019;24(1):68-81.

43. Kantaris X, Shevlin M, Porter J, Myers L. Development of the Thalassaemia Adult Life Index (ThALI). Health and Quality of Life Outcomes. 2020;18(1):180.

\section{Tables}

Table 1 Socio-demographic characteristics $(n=196)$ 


\begin{tabular}{|c|c|}
\hline Characteristics & $\mathrm{n}(\%)$ \\
\hline Age in years ${ }^{a}$ & $27(7.4)$ \\
\hline \multicolumn{2}{|l|}{ Gender } \\
\hline Male & $87(44)$ \\
\hline Female & $109(56)$ \\
\hline \multicolumn{2}{|l|}{ Ethnic } \\
\hline Malay & $121(62)$ \\
\hline Sabah and Sarawak indigenous (eg. Kadazan-Dusun) & $40(20)$ \\
\hline Chinese & $35(18)$ \\
\hline \multicolumn{2}{|l|}{ Types of thalassaemia } \\
\hline Beta thalassaemia major & $126(64)$ \\
\hline $\mathrm{HbE}$ beta thalassaemia & $59(30)$ \\
\hline $\mathrm{HbH}$ disease & $11(6)$ \\
\hline \multicolumn{2}{|l|}{ Types of comorbidity $(n=179)$} \\
\hline Musculoskeletal & $23(13)$ \\
\hline Endocrine & $21(12)$ \\
\hline Cardiovascular & $6(3)$ \\
\hline Blood infection & $4(2)$ \\
\hline Psychological & $4(2)$ \\
\hline Multiple & $16(9)$ \\
\hline Others & $6(3)$ \\
\hline \multicolumn{2}{|l|}{ Medication } \\
\hline Iron chelators & $191(97)$ \\
\hline Hormonal medication & $110(56)$ \\
\hline Cardiac medication & $8(4)$ \\
\hline More than 1 group of medication & $157(80)$ \\
\hline \multicolumn{2}{|l|}{ Mode of administration of iron chelating agents } \\
\hline \multicolumn{2}{|l|}{ Subcutaneous only } \\
\hline Oral only & $25(13)$ \\
\hline Combined oral and subcutaneous & $78(40)$ \\
\hline
\end{tabular}




\begin{tabular}{|lc|}
\hline None needed & $88(45)$ \\
Frequency of hospital visits $(\mathbf{n}=194)$ & $5(3)$ \\
Once a month & $80(41)$ \\
Twice a month & $70(36)$ \\
More than twice a month & $44(23)$ \\
\hline
\end{tabular}

aMean (SD)

Table 2 Chronic anaemia and dependency on blood transfusion $(n=196)$ 


\begin{tabular}{|c|c|c|c|c|c|}
\hline \multirow[t]{2}{*}{ Characteristics } & \multirow{2}{*}{$\begin{array}{l}\text { Total } \\
(n=196)\end{array}$} & \multirow{2}{*}{$p$ value } & \multicolumn{3}{|c|}{ Time of diagnosis and first transfusion } \\
\hline & & & $\begin{array}{l}\text { a Group } 1 \\
(n=85)\end{array}$ & $\begin{array}{l}{ }^{\mathrm{b}} \text { Group } 2 \\
(\mathrm{n}=22)\end{array}$ & $\begin{array}{l}{ }^{c} \text { Group } 2 \\
(n=89)\end{array}$ \\
\hline Type of thalassaemia & & 0.000 & & & \\
\hline Beta thalassaemia major & 126 & & 78 & 15 & 33 \\
\hline $\mathrm{HbE}$ beta thalassaemia & 59 & & 7 & 7 & 45 \\
\hline $\mathrm{HbH}$ disease & 11 & & 0 & 0 & 11 \\
\hline Presence of comorbidity & & 0.135 & & & \\
\hline Yes & 77 & & 41 & 8 & 28 \\
\hline No & 20 & & 39 & 14 & 49 \\
\hline Marital status & & 0.001 & & & \\
\hline Married & 41 & & 8 & 4 & 29 \\
\hline Single & 154 & & 77 & 18 & 59 \\
\hline Education & & 0.133 & & & \\
\hline Primary & 13 & & 7 & 2 & 4 \\
\hline Secondary & 133 & & 60 & 10 & 63 \\
\hline Tertiary & 50 & & 18 & 10 & 22 \\
\hline Employment status & & 0.147 & & & \\
\hline employed & 126 & & 57 & 10 & 59 \\
\hline unemployed & 70 & & 28 & 12 & 30 \\
\hline $\begin{array}{l}\text { General health perception } \\
\text { Good }\end{array}$ & & 0.946 & & & \\
\hline \multirow[t]{2}{*}{ Fair } & 145 & & 63 & 17 & 65 \\
\hline & 50 & & 22 & 5 & 23 \\
\hline $\begin{array}{l}\text { Satisfaction with general health } \\
\text { Good }\end{array}$ & & 0.386 & & & \\
\hline Fair & 100 & & 39 & 13 & 48 \\
\hline \multirow[t]{2}{*}{ Poor } & 83 & & 37 & 9 & 37 \\
\hline & 12 & & 8 & 0 & 4 \\
\hline
\end{tabular}


a Group 1: Thalassaemia diagnosed and started transfusion before age to 2 years old

${ }^{b}$ Group 2: Thalassaemia Diagnosed before 2 years old but first transfusion after 2 years old

${ }^{\mathrm{c}}$ Group 3: Thalassaemia diagnosed and started transfusion after age of 2 years old

Table 3 Self-perception of general health and quality of life

\section{CDC 'Healthy-days'}

Mean

(SD)

Number of days affected by physical issues (over 30 days) $(n=190)$

Number of days affected by mental issues (over 30 days) $(n=189)$

Number of days when activities were limited by physical and or mental issues (over 30 days) $(n=191)$

\section{WHOQOL-BREF}

Domain 1: Physical health* $(n=189)$

Domain 2: Psychological health* $(n=189)$

Domain 3: Social relationship* $(n=188)$

Domain 4: Environmental health* $(n=186)$

*A score closer to 100 indicates a better quality

Table 4 Linear regressions on sociodemographic, CDC healthy-days and employment associated with WHOQOL-BREF scores 
Factors

Factors

Physical health

Higher education

Days affected by physical issues (more days)

Days affected by mental issues (more days)

Days when activities were affected by physical and or mental issues (more days)

Discrimination at workplace before

Thalassaemia made job difficult (Yes)

Willingness to disclose (Yes)

Psychological health

Malay ethnic

Days affected by mental issues (more days)

Days when activities were affected by physical and or mental issues (more days)

Discrimination at workplace before

Thalassaemia made job difficult (Yes)

Willingness to disclose (Yes)

\section{Social relationship}

Higher education

Single

Days affected by mental issues (more days)

Discrimination at workplace before
Simple linear

regression

${ }^{a}$ Multiple linear

regression
$5.17(1.01, \quad 3.41(-1.14,7.97)$

$9.34)^{*}$

$\begin{array}{ll}-1.13(-1.92, & -0.60(-1.62,0.41) \\ -0.33)^{\star} & \end{array}$

$-1.02(-1.70$,
$-0.35)^{\star}$

$-0.14-1.01,0.73)$

$-1.58(-2.26$,

$-0.90)^{\star}$

$-1.22(-2.19$, $-0.25)^{*}$

$-10.79(-15.80, \quad 0.72(-12.3,-2.00)$ * $-5.77)^{*}$

$-6.64(-9.94$ $-3.35)$ *

$-1.35(-4.90,2,21)$

$3.41(-0.39,7.21) \quad 5.32(1.55,9.08)$ *
$4.01(1.15$,
$6.87)^{\star}$
$5.41(2.11,8.71)$ *

$-1.04(-1.72$,

$-0.35)^{\star}$

$-1.04(-1.97$, $-0.12)^{\star}$

$\begin{array}{ll}-1.03(1.75, & -0.29(-1.31,0.73) \\ -0.32)^{\star} & \end{array}$

$-8.93(-14.50$, $-3.36)^{*}$

$-2.76(-8.20,2.68)$

$-7.67(-10.97$, $-4.37)^{\star}$

$-5.80(-9.55$ $-2.04)^{\star}$

$7.83(4.09$, $11.58)$ *

$8.45(4.48,12.42)$ *

$5.26(0.92, \quad 3.04(-1.93,8.02)$
$9.61)^{\star}$

$\begin{array}{ll}-7.58(-13.15, & -12.70(-19.18, \\ -2.00)^{\star} & -6.22)^{\star}\end{array}$

$-1.10(-1.78, \quad-0.49(-1.43,0.45)$ $-0.43)^{\star}$

$-10.79(-16.33, \quad-7.06(-12.64$, $-5.24)^{\star}(-1.48)^{*}$ 


\begin{tabular}{|c|c|c|}
\hline Thalassaemia made job difficult (Yes) & $\begin{array}{l}-5.88(-9.36 \\
-2.39)^{\star}\end{array}$ & $-0.74(-.4 .58,3.10)$ \\
\hline Willingness to disclose (Yes) & $\begin{array}{l}4.96(1.06 \\
8.86)^{\star}\end{array}$ & $5.60(1.43,9.77)^{\star}$ \\
\hline \multicolumn{3}{|l|}{ Environmental health } \\
\hline Malay ethnic & $\begin{array}{l}3.23(0.11 \\
6.36)^{\star}\end{array}$ & $4.21(0.95,7.47)^{\star}$ \\
\hline Higher education & $\begin{array}{l}7.01(2.49 \\
11.52)^{\star}\end{array}$ & $5.84(1.09,10.58)^{*}$ \\
\hline Days affected by mental issues (more days) & $\begin{array}{l}-0.97(-1.72 \\
-0.23)^{\star}\end{array}$ & $-0.56(-1.47,0.34)$ \\
\hline Discrimination at workplace before & $\begin{array}{l}-11.45(-17.02 \\
-5.88)^{\star}\end{array}$ & $\begin{array}{l}-7.93(-13.30 \\
-2.57)^{\star}\end{array}$ \\
\hline Thalassaemia made job difficult (Yes) & $\begin{array}{l}-6.79(-10.38 \\
-3.19)^{\star}\end{array}$ & $-2.03(-5.74,1.68)$ \\
\hline Willingness to disclose (Yes) & $\begin{array}{l}9.46(5.66 \\
13.26)^{*}\end{array}$ & $\begin{array}{l}10.85(6.93 \\
14.77)^{*}\end{array}$ \\
\hline
\end{tabular}

${ }^{*} p<0.05$

${ }^{a}$ Adjusted to gender, ethnicity, education, marital status, factors in CDC healthy-days (days affected by physical issues, days affected by mental issues, days when activities were affected by physical and or mental issues), workplace issues (discrimination, thalassaemia made job more difficult, willingness to disclose status, had disclose status before)

Note: Factors which have no significant correlation in both simple and multiple linear regression were not displayed for the specified domain.

\section{Appendix}

Appendix I is not available with this version. 